\title{
MESOSTRATOSPHERIC LIDAR FOR THE HELIOGEOPHYSICAL COMPLEX
}

\section{G.G. Matvienko}

V.E. Zuev Institute of Atmospheric Optics SB RAS,

Tomsk, Russia,mgg@iao.ru

\section{V.N. Marichev}

V.E. Zuev Institute of Atmospheric Optics SB RAS,

Tomsk, Russia,marichev@iao.ru

\section{S.M. Bobrovnikov}

V.E. Zuev Institute of Atmospheric Optics SB RAS,

Tomsk,Russia,bsm@iao.ru

\author{
S.V. Yakovlev \\ V.E. Zuev Institute of Atmospheric Optics SB RAS, \\ Tomsk,Russia,ysv@iao.ru
}

A.Yu. Chistilin

S.A. Zverev Krasnogorsk Plant,

Krasnogorsk, Russia, a.chistilin@zenit-kmz.ru

V.A. Sautkin

S.A. Zverev Krasnogorsk Plant,

Krasnogorsk,Russia,sautkin@zenit-kmz.ru

\begin{abstract}
The Heliogeophysical Complex of RAS, which is developing at the Institute of Solar-Terrestrial Physics SB RAS in the Irkutsk region, includes instruments for studying the Sun, the upper atmosphere and the mesostratospheric lidar system (MS lidar) for analyzing the neutral part of the atmosphere from Earth's surface to the thermosphere (100-110 km altitude). More specifically, the objective of the MS lidar is to measure profiles of thermodynamic parameters of the atmosphere and the altitude distribution of the aerosolgas composition. To solve these problems, the MS lidar ensures the use of several laser sensing methods at a number of specially selected laser wavelengths in the
\end{abstract}

total range $0.35-1.1 \mu \mathrm{m}$. In this case, the following types of scattering are used: molecular, aerosol, Raman, resonance, as well as differential absorption, Doppler broadening and shift of the spectrum of scattered radiation. The article describes the methods used in the MS lidar and the measured atmospheric characteristics.

Keywords: laser sensing, stratosphere, mesosphere, lidar, atmospheric thermodynamics.

\section{INTRODUCTION}

Global monitoring of the atmosphere in different layers (troposphere, stratosphere, mesosphere, and thermosphere) is an important task directly connected with the problem of monitoring climate changes under the influence of natural and anthropogenic processes. Research in this direction is carried out under global programs such as the U.S. Global Change Program and its important component Coupling Energetic and Dynamics of Atmospheric Regions. A key role in implementing these programs is assigned to lidars as advanced instruments capable of studying at new qualitative and quantitative levels the state and composition of the atmosphere to high altitudes with high temporal and spatial resolution. The use of many sensing methods in the lidars makes it possible to obtain a wide range of profile characteristics of physical quantities and aerosolgas composition of the atmosphere. Comprehensive information on atmospheric parameters gives insight into processes that occur throughout the atmosphere and are induced by both external (solar, magnetospheric, volcanic, and seismic activity) and internal (gravity and planetary waves, stratospheric warming events) factors and phenomena they generate. The layers of the upper atmosphere containing charged particles are successfully studied using radiophysical complexes. Neutral atmospheric layers in the monitoring mode can be examined by lidar systems. The combination of both the approaches in the Heliogeophysical Complex will enable the systematic analysis of the relationships existing between neutral and charged layers of the atmosphere. Laws of these relationships are currently being discussed on the basis of results of episodic experiments, e.g. [Polyakova et al., 2015; Czin Czyao et al., 2017; Yasyukevich et al., 2018; Polekh et al., 2019].

It is impossible to study the upper atmospheric layers such as the mesosphere and thermosphere, which are still poorly understood, without lidars with large optics and high-power lasers, which is supposed to be realized with maximum possible parameters in the mesostratospheric lidar (MS lidar). The closest Russian analogue of the MS lidar is the multichannel measuring complex Siberian Lidar Station, Tomsk $\left(56.48^{\circ} \mathrm{N}, 85.05^{\circ} \mathrm{E}\right)$ [Matvienko et al., 2016], included in the List of Unique Experimental Systems of the Russian Federation in 1995. The closest foreign analogue of the MS lidar is the Rayleigh/Mie/Raman lidar (RMR lidar, Alomar Observatory, island of Andøya, Northern Norway (69.28 $\mathrm{N}$, $16.01^{\circ}$ E) [von Zahn et al., 2000; Schoch et al., 2008] the cooperative development of Norwegian, German, and French researchers. Estimates of signal levels made from the projected parameters of the MS lidar show that it is expected to take the MS lidar three-four less time to gain the same information about the atmosphere than it takes for the RMR lidar. According to the project, with an approximately equal area of the main antenna of the MS lidar and areas of two antennas of the RMR lidar the laser pulse energy of the MS lidar will be more than 
four times greater than that of the RMR lidar. In addition, the MS lidar will use a laser source with the radiation spectrum suitable to receive resonance scattering lidar signals in sodium vapor whose layer is at $85-110$ $\mathrm{km}$ altitudes. This makes this project unique.

The MS lidar is designed for real-time acquisition of data on physical parameters of the atmosphere in an altitude range $10-100 \mathrm{~km}$ with high spatial and temporal resolution.

\section{TECHNICAL CONFIGURATION OF THE MS LIDAR}

The MS lidar is designed to study profile characteristics of physical parameters (temperature, wind) and composition (number of gas components, aerosol) of the middle and upper atmosphere, which are formed under the influence of natural and anthropogenic processes [Matvienko et al., 2014]. This information must be obtained simultaneously with data provided by radiophysical and other methods of studying solar-terrestrial relations, in particular in the daytime. The work in the daytime imposes very high requirements for energy potential and block of spectral-spatial selection of background light of the lidar.

In [Matvienko et al., 2010], we have described the methodology of selecting parameters of the main lidar units determining its potential on the assumption of twenty-four-hour maintenance of its operation up to 100 $\mathrm{km}$ through the cloud-free troposphere (or gaps between the clouds). In [Matvienko et al., 2016], we have demonstrated the energy potential of the MS lidar (the product of laser pulse energy and receiving antenna area) equal to $8-10 \mathrm{~J} \cdot \mathrm{m}^{2}$ with a pulse repetition rate of 30 Hz. Most laser pulse energy can be realized by synchronously sending pulses of several lasers such as Continuum Powerlight 90-30. A large receiving antenna (the required area is $4.7 \mathrm{~m}^{2}$ ) can be created by a system of six mirrors, structurally combined into a single unit, which allows for a tilt up to $30^{\circ}$ from the vertical without misalignment of axes of the mirrors.

The transceiving antenna unit is a set of receiving mirror telescopes and transmitting collimators integrated structurally in such a way that optical axes of all the antennas are parallel. In addition, the unit includes a swivel mirror and laser sources (Figures 1,2). All elements of the unit are combined with the necessary degree of fixity so that when receiving and transmitting antennas are tilted in a range of zenith angles from 0 to $30^{\circ}$, the parallel alignment of axes must be unchanged — the permissible misalignment of optical axes of collimators and the optical axis of receiving antenna (telescope) is no more than 5 arcsec.

The use of mirror optics allows operation of many laser sources with different wavelengths. To improve the performance reliability of the lidar requires cold redundancy of laser sources. The receiving antenna has an area of $4.7 \mathrm{~m}^{2}$. The multi-lobe antenna pattern [Kaul, 1987] is implemented by using various parts of the focal plane located symmetrically in the vicinity of the optical axis of the receiving optical system.

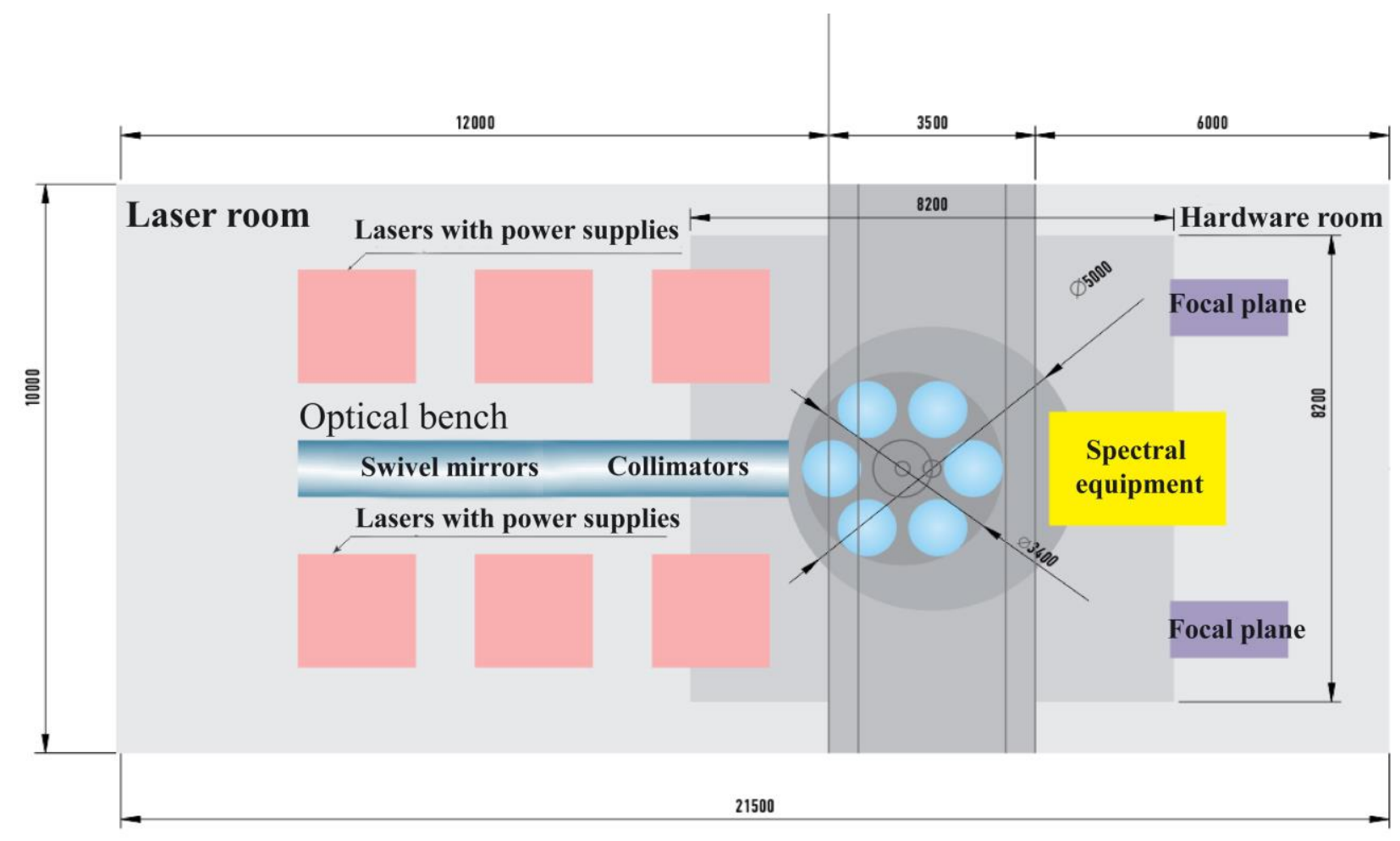

Figure 1. Arrangement of the main elements of the lidar 


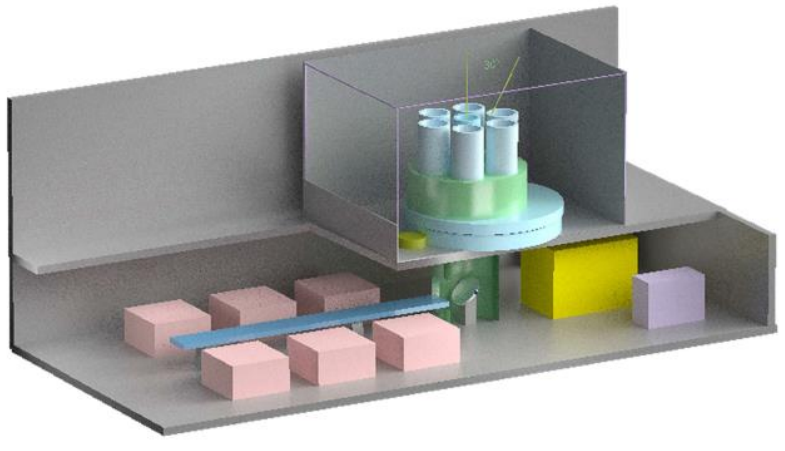

Figure 2. Technical configuration of the lidar

To solve the problems of monitoring, synchronous operation of channels is not needed. There may be a need to synchronize several lasers to increase the pulse energy in order to improve the signal/noise ratio. The working orientation of the lidar axis is in the zenith angle range $0-30^{\circ}$.

\section{SENSING METHODS AND MEASUREMENT MODES}

The MS lidar is designed for remote identification of the following atmospheric parameters: temperature, density, wind speed, ozon content, sodium vapor distribution in the mesosphere. Tables 1-7 list technical specifications of measurements.

Table 1

MS-lidar parameters for measuring temperature and wind speed to $80-90 \mathrm{~km}$ altitudes, using method 1.1

\begin{tabular}{|l|l|}
\hline \multicolumn{1}{|c|}{ Laser type } & $\begin{array}{c}\text { Nd:YAG } \\
\text { (third harmonic) }\end{array}$ \\
\hline Wavelength $\lambda, \mathrm{nm}$ & 355 \\
\hline Radiation pulse energy $E, \mathrm{~J}$ & 0.4 \\
\hline Pulse repetition rate $f, \mathrm{~Hz}$ & 30 \\
\hline Laser emission linewidth, $\mathrm{nm}$ & 0.005 \\
\hline Radiation divergence, microrad & 100 \\
\hline Pulse length, ns & 8 \\
\hline Receiving antenna area, $\mathrm{m}^{2}$ & 4.7 \\
\hline
\end{tabular}

Table 2

MS-lidar parameters for measuring temperature to $80-90 \mathrm{~km}$ altitude, using method 1.2

\begin{tabular}{|c|c|}
\hline Laser type & $\begin{array}{l}\text { Nd:YAG (second, } \\
\text { third harmonics) }\end{array}$ \\
\hline Wavelength $\lambda, \mathrm{nm}$ & $\begin{array}{l}355 \\
532 \\
\end{array}$ \\
\hline $\begin{array}{l}\text { Radiation pulse energy } E, J \\
\text { for } \lambda=355 \mathrm{~nm} \\
\text { for } \lambda=532 \mathrm{~nm}\end{array}$ & $\begin{array}{l}0.4 \\
0.8\end{array}$ \\
\hline Emission bandwidth, pm & 5 \\
\hline Pulse repetition rate $f, \mathrm{~Hz}$ & 30 \\
\hline Radiation divergence, microrad & less than 0.1 \\
\hline Pulse length, ns & 8 \\
\hline Receiving antenna area, $\mathrm{m}^{2}$ & 4.7 \\
\hline
\end{tabular}

Table 3

MS-lidar parameters for measuring temperature and wind speed at $90-110 \mathrm{~km}$ altitudes

\begin{tabular}{|l|l|}
\hline Laser type & Nd:YAG \\
\hline Wavelength $\lambda, \mathrm{nm}$ & $\begin{array}{l}1064 \\
1319\end{array}$ \\
\hline Acquiring method & $\begin{array}{l}\text { summation } \\
\text { of frequencies }\end{array}$ \\
\hline $\begin{array}{l}\text { Central radiation wavelength, } \\
\mathrm{nm}\end{array}$ & 589.150 \\
\hline Radiation pulse energy E, $\mathrm{J}$ & 0.1 \\
\hline Pulse repetition rate $\mathrm{f}, \mathrm{Hz}$ & 30 \\
\hline $\begin{array}{l}\text { Width of radiation line } \\
\text { spectrum, MHz }\end{array}$ & 100 \\
\hline Radiation line tuning range, $\mathrm{nm}$ & 0.005 \\
\hline Radiation divergence, microrad & 100 \\
\hline Pulse length, ns & 8 \\
\hline Receiving antenna area, m2 & 4.7 \\
\hline
\end{tabular}

Table 4

MS-lidar parameters for measuring temperature to $30-40 \mathrm{~km}$ altitudes, using method 3.1

\begin{tabular}{|l|l|}
\hline \multicolumn{1}{|c|}{ Laser type } & \multicolumn{1}{c|}{\begin{tabular}{c|} 
Nd:YAG \\
(second harmonic)
\end{tabular}} \\
\hline Wavelength $\lambda, \mathrm{nm}$ & 532 \\
\hline Radiation pulse energy $E, \mathrm{~J}$ & 0.8 \\
\hline Pulse repetition rate $f, \mathrm{~Hz}$ & 30 \\
\hline Radiation spectrum width, $\mathrm{nm}$ & 0.1 \\
\hline Pulse length, ns & 8 \\
\hline Receiving antenna area, $\mathrm{m}^{2}$ & 4.7 \\
\hline
\end{tabular}

MS-lidar parameters for measuring temperature to 30-40 $\mathrm{km}$ altitude, using method 3.2

\begin{tabular}{|l|l|}
\hline \multicolumn{1}{|c|}{ Laser type } & $\begin{array}{c}\text { Nd:YAG (second, } \\
\text { third harmonics) }\end{array}$ \\
\hline Wavelength $\lambda, \mathrm{nm}$ & 355 \\
& 532 \\
\hline Radiation pulse energy $E, \mathrm{~J}$ & \\
for $\lambda=355 \mathrm{~nm}$ & 0.4 \\
for $\lambda=532 \mathrm{~nm}$ & 0.8 \\
\hline Radiation spectrum width, $\mathrm{nm}$ & 0.1 \\
\hline Pulse repetition rate $f, \mathrm{~Hz}$ & 30 \\
\hline Radiation divergence, $\mathrm{microrad}$ & less than 0.1 \\
\hline Pulse length, $\mathrm{ns}$ & 8 \\
\hline Receiving antenna area, $\mathrm{m}^{2}$ & 4.7 \\
\hline
\end{tabular}

\section{Temperature and wind speed measurements to $80-90 \mathrm{~km}$ altitudes}

The main theoretical and experimental groundwork for this sensing method is presented in [Bondarenko et al., 1994; Marichev, 2011a, b, 2013].

1.1. Measuring the Doppler broadening and frequency shift of the line center of backscattered laser radiation

To measure the wind speed, the optical axis of the MS lidar is tilted by $30^{\circ}$ from the direction of the zenith 
Table 6 through the pressure $p(H)$ by the known law of ideal

MS-lidar parameters for measuring ozone concentration at $12-35 \mathrm{~km}$ altitudes

\begin{tabular}{|l|l|}
\hline \multicolumn{1}{|c|}{ Laser type } & \multicolumn{1}{c|}{$\begin{array}{c}\text { excimer } \\
\text { XECI }\end{array}$} \\
\hline $\begin{array}{l}\text { Wavelength } \lambda, \mathrm{nm} \\
\text { 1st Stokes component with } \\
\text { high-pressure cell } \mathrm{H}_{2}\end{array}$ & 308 \\
\hline Radiation pulse energy $E, \mathrm{~J}$ & 353 \\
\hline Pulse repetition rate $f, \mathrm{~Hz}$ & $50 \cdot 10^{-3}$ \\
\hline Radiation spectrum width, $\mathrm{nm}$ & 100 \\
\hline Radiation divergence, microrad & $\leq 2$ \\
\hline Pulse length, ns & $100 \times 300$ \\
\hline Receiving antenna area, $\mathrm{m}^{2}$ & 20 \\
\hline
\end{tabular}

Table 7

MS-lidar parameters for studying spatiotemporal aerosol distribution at $12-100 \mathrm{~km}$ altitudes

\begin{tabular}{|l|l|}
\hline \multicolumn{1}{|c|}{ Laser type } & Nd:YAG \\
\hline & 355 \\
Wavelength $\lambda, \mathrm{nm}$ & 532 \\
& 1064 \\
\hline Radiation pulse energy $E, \mathrm{~J}$ & \\
for $\lambda=355 \mathrm{~nm}$ & 0.4 \\
for $\lambda=532 \mathrm{~nm}$ & 0.8 \\
for $\lambda=1064 \mathrm{~nm}$ & 1.6 \\
\hline Radiation spectrum width, MHz & 100 \\
\hline Pulse repetition rate $f, \mathrm{~Hz}$ & 30 \\
\hline Pulse length, $\mathrm{ns}$ & 8 \\
\hline Receiving antenna area, $\mathrm{m}^{2}$ & 4.7 \\
\hline
\end{tabular}

(three measurements at different azimuth angles are needed).

1.2. Determination of temperature stratification from molecular (Rayleigh) light scattering

The lidar equation determining the value of a received signal in the approximation of single elastic scattering has the form

$$
N(H)=C P^{2} G(H)\left[\beta_{\mathrm{a}}(H)+\beta_{\mathrm{m}}(H)\right] H^{-2}+N_{\mathrm{TM}},
$$

where $H$ is the height (in the generalized case, distance); $N(H)$ is the lidar signal from $H$, measured in units of current or voltage in detecting light fluxes in an analog form or from the number of photocounts during detection in the photon counting mode; $\beta_{\mathrm{a}}(H), \beta_{\mathrm{m}}(H)$ are the coefficients of aerosol and molecular backscattering; $C$ is the instrumental constant of the lidar including the receiving telescope area, transceiver path transmission, laser pulse energy, quantum efficiency of photodetector; $G(H)$ is the lidar geometrical form factor which takes into account the overlap of the laser beam and the antenna field of view; $P(H)$ is the atmospheric layer transmittance from the lidar to $H$ in the laser wavelength; $N_{\mathrm{TM}}$ is the total background and dark noise, estimated in the same values as the lidar signal.

Lidar measurements of vertical temperature distribution from Rayleigh scattering are based on the unambiguous relationship between the coefficient of molecular backscattering $\beta_{\mathrm{m}}(H)$ and the atmospheric density $q(H)$ for $H$. In turn, according to lidar equation (1), echo signals are proportional to $\beta_{\mathrm{m}}(H)$, whereas the atmospheric density is related to the temperature $T(H)$ gas state:

$$
p(H)=R^{*} q(H) T(H),
$$

where $R^{*}$ is the specific gas constant; $g(H)$ is the free fall acceleration.

If the hydrostatic equilibrium condition holds

$$
d p(H)=-q(H) g(H) d(H)
$$

and there are no aerosol layers in the altitude range of interest, we can find a relationship between temperature and lidar signals ( $g(H)$ is the free fall acceleration). We have derived an expression for temperature in the form of

$$
\begin{aligned}
& T(H)=\frac{P^{2}(H)}{N(H) H^{2}} \times \\
& \times\left[\frac{N\left(H_{\mathrm{m}}\right) H_{\mathrm{m}}^{2} T\left(H_{\mathrm{m}}\right)}{P^{2}\left(H_{\mathrm{m}}\right)}+\frac{1}{R^{*}} \int_{H_{\mathrm{m}}}^{H} \frac{N(h) h^{2} g(h) d h}{P^{2}(h)}\right],
\end{aligned}
$$

where $H_{\mathrm{m}}$ is the so-called height of calibration, at which boundary temperature values $T\left(H_{\mathrm{m}}\right)$ are specified.

For daytime measurements, we use spectral filtering with an interference light filter and double Fabry-Perot interferometer; for nighttime measurements, only the interference filter.

Profiles of the temperature measured by the IAO SB RAS lidar with a $1 \mathrm{~m}$ receiving mirror from signals of Rayleigh scattering are shown in Figure 3.

\section{Temperature and wind speed measurements at $90-110 \mathrm{~km}$ altitudes}

The measurements are made using the resonance scattering in sodium vapor. The wind speed range is from -130 to $130 \mathrm{~m} / \mathrm{s}$; the temperature range is $150-200 \mathrm{~K}$, the spatial resolution is $500 \mathrm{~m}$.

One of the promising options to obtain the probe radiation with parameters providing the necessary adjustment region and radiation spectrum width is the summation of Nd:YAG-laser frequencies with wavelengths of 1064 and $1319 \mathrm{~nm}$ [Kawahara et al., 2011]. Estimates show that at night the temperature with an error of 1-2 $\mathrm{K}$ at altitudes of 85 to $105 \mathrm{~km}$ with the method of resonance scattering in sodium vapor can be determined when the signal accumulation time is $\sim 30 \mathrm{~min}$.

The performance of the lidar in wind speed measurements from resonance scattering by sodium atoms involves determining the frequency shift of the Doppler contour of scattering.

\section{Temperature measurement to $30-40 \mathrm{~km}$ altitudes}

3.1. Temperature measurement from pure rotational spectra of spontaneous Raman scattering (SRS) by nitrogen and oxygen molecules

It is necessary to use a special double grating monochromator developed by IAO SB RAS.

A lidar signal in the photon-counting mode for a separate line of pure rotational spectrum of SRS by nitrogen or oxygen molecules can be represented as follows: 


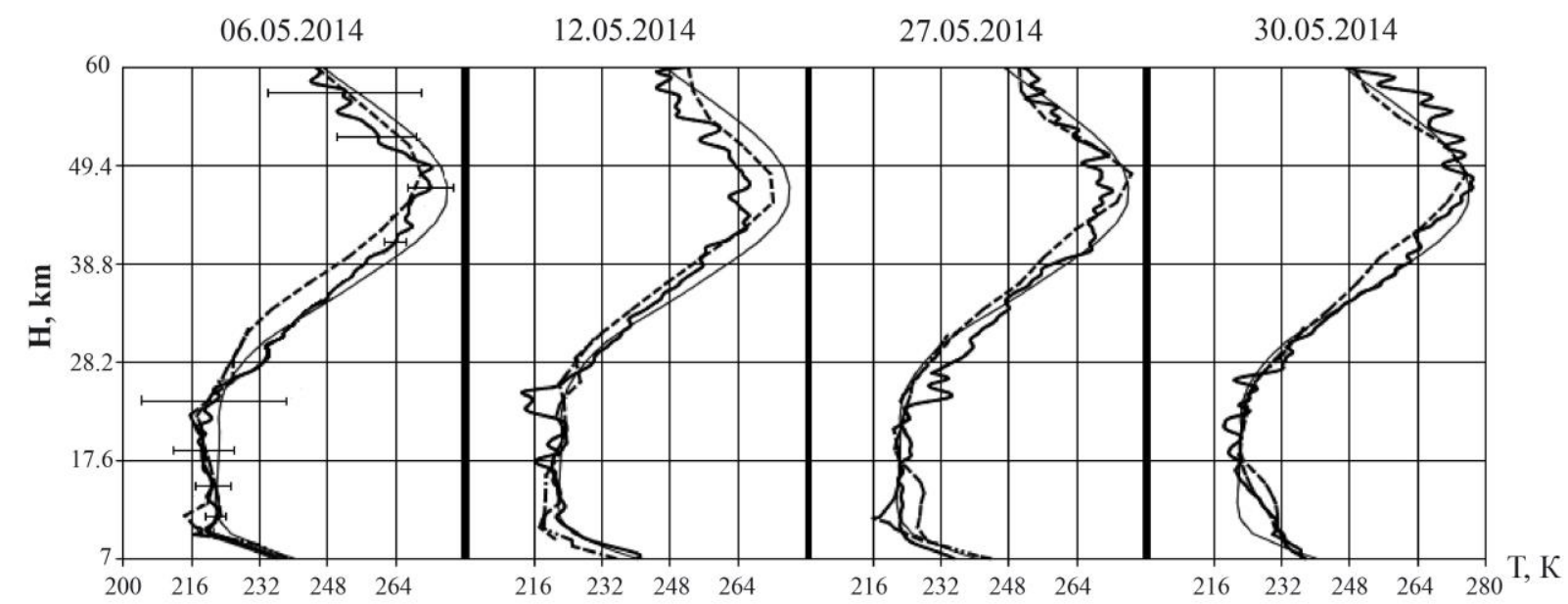

Figure 3. Lidar temperature profiles (thick solid line) versus temperature profiles obtained by the Aura satellite (dashed curve) and radiosondes (dash-dot curves), and the CIRA-86 model [Rees et al., 1990] (thin solid line)

$$
\begin{aligned}
& n_{i}(H)=\frac{W \eta}{h v_{0}} \frac{\pi D^{2}}{4 H^{2}} K G(H) \beta_{i}(H) \frac{c \tau}{2} \times \\
& \times \exp \left(-\int_{0}^{H}\left(\alpha\left(v_{0}, x\right)+\alpha\left(v_{i}, x\right)\right) d x\right),
\end{aligned}
$$

where $H$ is the distance to the scattering volume; $c$ is the velocity of light; $\tau$ is the laser pulse length; $W$ is the pulse energy; $h$ is the Planck constant; $v_{0}$ is the laser radiation frequency; $K$ is the transmittance of transmitting and receiving optics; $\eta$ is the quantum efficiency of the photodetector; $D$ is the diameter of the receiving telescope; $\beta_{i}(r)$ is the profile of the volume backscattering coefficient for the $i$ th line of pure rotational spectrum of SRS; $c \tau / 2$ determines the length of the scatter- ing volume along the sounding path; $\alpha(v, x)$ is the profile of atmospheric attenuation coefficient for the frequency $v ; x$ is the variable of integration along the sounding path.

To implement the temperature measurement methods, four regions of pure rotational spectrum of SRS with opposite temperature dependence are used. The mutual arrangement of the regions is shown in Figure 4. Lines with negative temperature dependence of intensity form two spectral regions and combine in one channel:

$$
n_{-}=\left(\sum_{\Delta v_{i} \in \Delta v_{-}}\left(n_{i}^{\mathrm{N}_{2}}+n_{i}^{\mathrm{O}_{2}}\right)\right)^{\text {stokes }}+\left(\sum_{\Delta v_{i} \in \Delta v_{-}}\left(n_{i}^{\mathrm{N}_{2}}+n_{i}^{\mathrm{O}_{2}}\right)\right)^{\text {antistokes }} .
$$

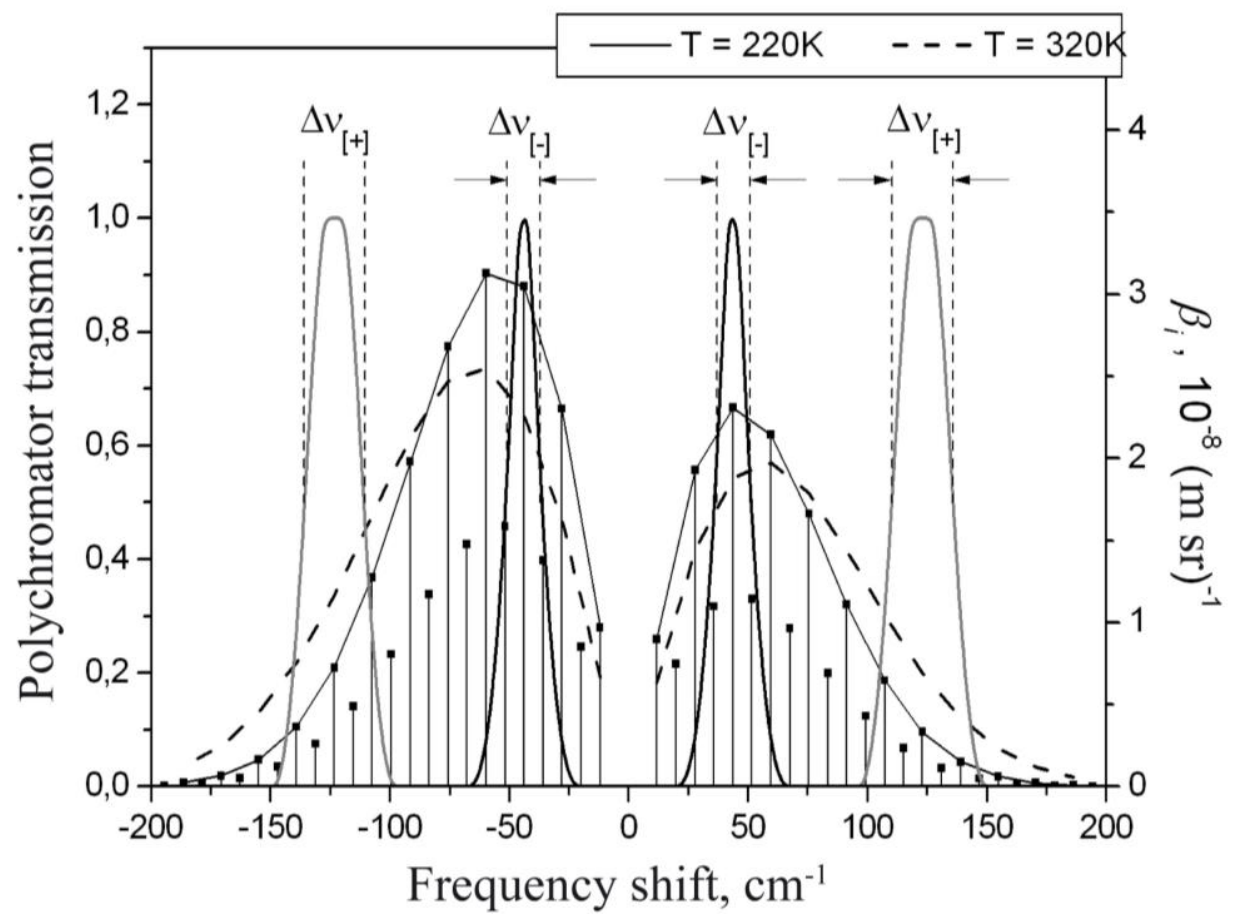

Figure 4. Polychromator function and envelopes of the pure rotational spectrum of nitrogen Raman scattering for 220 and 320 K. Oxygen Raman scattering spectra are not shown 
For brevity, hereinafter the scheme of summation and combination of the lines during the formation of informative intervals, in this case $n_{-}$and $n_{+}$with negative and positive temperature dependence respectively, is written in symbolic terms. The expression $\Delta v_{i} \in \Delta v_{-}$, defining limits of the summation, means that for the selected frequency range $\Delta v_{-}$all the lines having frequency shifts $\Delta v_{i}$ within this range are summed up. The same applies to other sums given below.

Lines in spectral regions with positive dependence combine in another channel:

$$
\begin{aligned}
& n_{+}=\left(\sum_{\Delta v_{i} \in \Delta v_{+}}\left(n_{i}^{\mathrm{N}_{2}}+n_{i}^{\mathrm{O}_{2}}\right)\right)^{\text {stokes }}+ \\
& +\left(\sum_{\Delta v_{i} \in \Delta v_{+}}\left(n_{i}^{\mathrm{N}_{2}}+n_{i}^{\mathrm{O}}\right)\right)^{\text {antistokes }} .
\end{aligned}
$$

Both intensity and temperature sensitivities of symmetric Stokes and anti-Stokes lines of the rotational Raman scattering spectrum have close values. This makes their use for measuring temperature almost equally effective.

The signal ratio in two spectral regions combining lines with positive (negative) temperature dependence,

$$
\begin{aligned}
& N_{-}=n_{-} \Delta t, \\
& N_{+}=n_{+} \Delta t,
\end{aligned}
$$

accumulated in the time span $\Delta t$, required to achieve an excess of the desired signal over noise, does not contain any distance-dependent lidar function components:

$$
R=\frac{\sum_{\mathrm{N}_{2}, \mathrm{O}_{2}} \sum_{\Delta v_{i} \in \Delta v_{-}} C_{i}\left(K_{i}^{\mathrm{S}}\left(\mathrm{v}_{0}-\Delta \mathrm{v}_{i}\right)^{4} \exp \left(\frac{h c F_{i}}{k T}\right)+K_{i}^{\mathrm{AS}}\left(v_{0}+\Delta v_{i}\right)^{4} \exp \left(-\frac{h c F_{i+2}}{k T}\right)\right)}{\sum_{\mathrm{N}_{2}, \mathrm{O}_{2}} \sum_{\Delta v_{i} \in \Delta \mathrm{v}_{+}} C_{i}\left(K_{i}^{\mathrm{S}}\left(\mathrm{v}_{0}-\Delta \mathrm{v}_{i}\right)^{4} \exp \left(\frac{h c F_{i}}{k T}\right)+K_{i}^{\mathrm{AS}}\left(v_{0}+\Delta v_{i}\right)^{4} \exp \left(-\frac{h c F_{i+2}}{k T}\right)\right)} .
$$

Superscripts $S$ and $A S$ of $K_{i}$ represent Stokes or antiStokes components respectively;

$F_{J}=B J(J+1)-d[J(J+1)]^{2}$ is the rotational term of oxygen or nitrogen molecule, where $J$ is the rotational quantum number, in this case, $J=i$ or $J=i+2 ; B$ and $d$ are the rotational constant and the constant of centrifugal stretching of nitrogen or oxygen molecule respectively. The function $R(T)$, defined by (3), for the polychromator function (see Figure 4) is shown in Figure 5. The transformation function $R(T)$ as a lidar function can be calculated from initial parameters of the lidar or obtained from calibration. The analytical form of $R(T)$, obtained from calibration, may be set by polynomial approximation in inverse powers of $T$ :

$$
R=\exp \left(\sum_{k=0}^{n} \frac{A_{k}}{T^{k}}\right) .
$$

As estimates show, in the range of temperature variation from 200 to $300 \mathrm{~K}$ the linear polynomial approximation error is $\sim 1 \mathrm{~K}$, and $R(T)$ can be represented as

$$
\begin{aligned}
& R=\frac{N_{-}}{N_{+}}= \\
& =\frac{\sum_{\substack{\text { stokes } \\
\text { antistokes }}} \sum_{\mathrm{N}_{2}, \mathrm{O}_{2}} \sum_{\Delta v_{i} \in \Delta v_{-}} K_{i} \beta_{i} \exp \left(-\int_{0}^{r} \alpha\left(v_{i}, x\right) d x\right)}{\sum_{\substack{\text { stokes } \\
\text { antistokes }}} \sum_{\mathrm{N}_{2}, \mathrm{O}_{2}} \sum_{\Delta v_{i} \in \Delta v_{+}} K_{i} \beta_{i} \exp \left(-\int_{0}^{r} \alpha\left(v_{i}, x\right) d x\right)},
\end{aligned}
$$

which makes its use convenient for measuring the air temperature. The coefficient $K_{i}$ describes the effectiveness of the chain transmitter-receiver-detector for an individual spectral line.

Since we can ignore the spectral dependence of atmospheric attenuation coefficients for different regions of pure rotational SRS spectra [Matvienko et al., 2016], Expression (2) is simplified:

$$
R=\frac{\sum_{\substack{\text { stokes } \\ \text { antistokes }}} \sum_{\mathrm{N}_{2}, \mathrm{O}_{2}} \sum_{\Delta v_{i} \in \Delta v_{-}} K_{i} \beta_{i}}{\sum_{\substack{\text { stokes } \\ \text { antistokes }}} \sum_{\mathrm{N}_{2}, \mathrm{O}_{2}} \sum_{\Delta v_{i} \in \Delta v_{-}} K_{i} \beta_{i}} .
$$

Substituting the $\beta_{i}$ values known from the theory of SRS spectra [Spelsberg, Meyer, 1999], we obtain Expression (3) for $R$ containing an explicit temperature dependence:

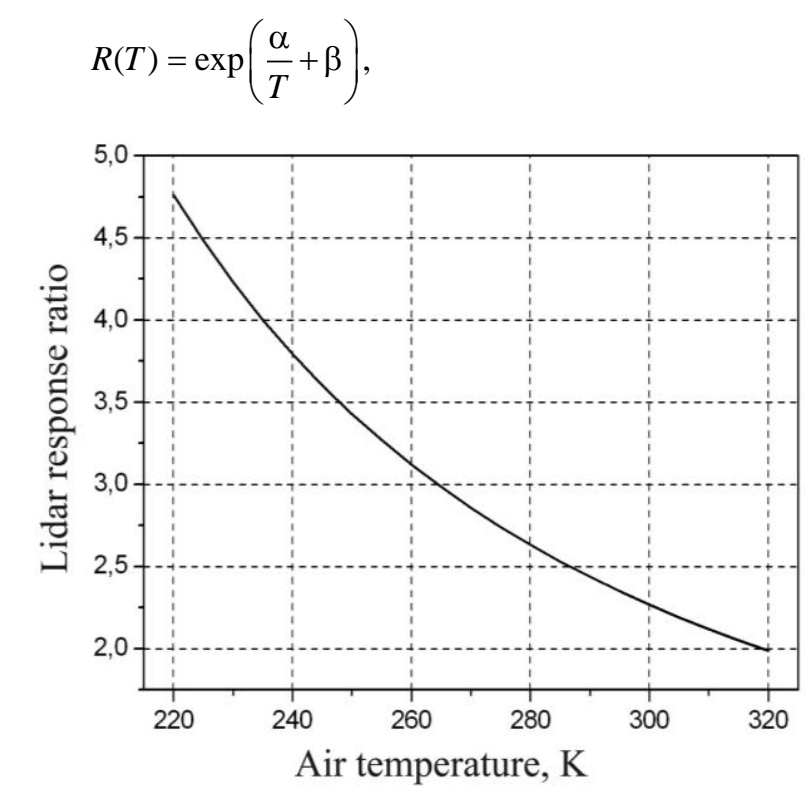

Figure 5. Signal ratio versus air temperature for the position of spectral bandpasses in Expression (3) shown in Figure 4 
where $\alpha$ and $\beta$ are the constant coefficients determined during lidar calibration.

Temperature sensitivity (profile steepness) of the $R(T)$ ratio is determined by the temperature dependence and the intensity of isolated spectral lines. The signal accumulation time depends on the overall intensity of the selected spectral region. Obviously, the choice of the correct combination of spectral lines in the regions provides maximum sensitivity of the lidar with a minimum measurement time.

Our estimates show that this method for the lidar parameters presented in Table 4 will allow us to measure the temperature with an accuracy of $1 \mathrm{~K}$ and spatial resolution $0.5-1 \mathrm{~km}$ to $\sim 50 \mathrm{~km}$ altitudes. In this case, the signal acquisition time will be $1 \mathrm{hr}$.

3.2. Temperature measurement from spectra of vibrational-rotational Raman scattering by nitrogen molecules

When measuring temperature to $40 \mathrm{~km}$ altitudes from spectra of the vibrational-rotational Raman scattering by nitrogen molecules [Zuev et al., 1996a], the second and third harmonics of the Nd:YAG laser (532 and $355 \mathrm{~nm}$ ) are utilized. Lidar signals are received at SRS wavelengths of 608 and $387 \mathrm{~nm}$.

Lidar equation (1) for a vibrational-rotational Raman scattering by molecules in a single-scattering approximation can be transformed into

$$
N(H)=C G(H) P^{2}(H) \beta_{\mathrm{R}}(H) H^{-2}+N_{\mathrm{TM}},
$$

where $\beta_{\mathrm{R}}(H)$ is the back SRS coefficient. Data on the temperature determined by the SRS method is provided by the backscatter coefficient $\beta_{\mathrm{R}}=\sigma_{\mathrm{R}} n$ both through the scattering cross-section $\sigma_{\mathrm{R}}$ and through sounded gas molecule density $n$. This very feature has determined two ways of implementing the SRS lidar method: using pure rotational or vibrational-rotational $\mathrm{Ra}$ man scattering spectrum.

The temperature profiles were reconstructed from SRS signals, using the nitrogen density, i.e. the atmospheric density. To calculate the temperature $T$ from SRS signals, we have derived an expression analogous to that for calculating the temperature from Rayleigh scattering signals:

$$
\begin{aligned}
& T(H)=\frac{P_{1}(H) P_{2}(H)}{N(H) H^{2}} \times \\
& \times\left[\frac{N\left(H_{\mathrm{m}}\right)}{P_{1}\left(H_{\mathrm{m}}\right) P_{2}\left(H_{\mathrm{m}}\right)} T\left(H_{\mathrm{m}}\right)-\frac{1}{R^{*}} \int_{H_{\mathrm{m}}}^{H} \frac{N(x) h^{2} g(x) d x}{P_{1}(x) P_{2}(x)}\right],
\end{aligned}
$$

where $P_{1}(H), P_{2}(H)$ is the atmospheric transmittance from the lidar to $H$ at wavelengths of 532 and $607 \mathrm{~nm}$.

We use interference light filters with a bandpass of $0.5 \mathrm{~nm}$

\section{Measurement of ozone concentration at 12-35 $\mathrm{km}$ by the differential absorption method}

The main theoretical and experimental groundwork for this sensing method is presented in [Elnikov et al., 1989, 1992; Burlakov et al., 1993; Marichev et al., 1996; Zuev et al., 1996b].

The method is based on the differential absorption of two radiations with different wavelengths in spectral re- gions with stronger $\left(\lambda_{1}\right)$ and weak $\left(\lambda_{2}\right)$ absorption of the gas under study. If two multiple-wave laser pulses are within a fairly narrow spectral range, their scattering coefficients in the atmosphere may be considered practically constant depending on wavelength. If radiation pulses are sent into the atmosphere at least for a time not exceeding the time of the frozen turbulence of the atmosphere, we may also neglect spatiotemporal variations of scattering characteristics. In this case, the gas concentration $n(H)$ is determined by the known formula [Elnikov et al., 1989]

$$
\begin{aligned}
& n(H)=\frac{1}{2\left[\sigma\left(\lambda_{1}, H\right)-\sigma\left(\lambda_{2}, H\right)\right]} \times \\
& \times \frac{d}{d H} \ln \frac{N\left(\lambda_{2}, H\right)}{N\left(\lambda_{1}, H\right)},
\end{aligned}
$$

where $\sigma\left(\lambda_{1}, H\right)$ and $\sigma\left(\lambda_{2}, n\right)$ are the absorption crosssections inside and outside the absorption gas lines, which are related with volume molecular absorption coefficients by a simple relation

$$
\alpha_{\Pi}(\lambda, H)=n(H) \sigma(\lambda, H) .
$$

Note that Expression (4) was derived when implementing the differential absorption method for the simplest case, i.e. when using isolated gas absorption lines. A typical example of such an implementation is sounding of the water vapor layer having narrow $\mathrm{H}_{2} \mathrm{O}$ absorption lines in the visible and near IR spectral regions [Browell et al., 1979; Zuev et al., 1981; Zuev et al., 1983]. Despite the apparent simplicity of Formula (4), the practical implementation of the differential absorption method in the classic form is difficult due to the severe restrictions imposed primarily on spectral characteristics of radiation. Laser radiation must be highly monochromatic, have a stable spectral line, and allow fine adjustments to an isolated absorption line profile [Zuev, Zuev, 1992].

Another option for implementation of the method is to use gas absorption bands. It is widely used for sounding the stratospheric ozone. In stratospheric ozone lidars, a $\mathrm{XeCl}$ excimer laser with a wavelength of $308 \mathrm{~nm}$ falling on the Huggins UV absorption band is generally utilized as a transmitter. Because of low selectivity and large Huggins spectral absorption bandwidth (from 300 to $330 \mathrm{~nm}$ ), the second reference wavelength must be shifted from the main one by more than 20-30 nm toward its increase to ensure the required level of difference in the absorption. The work with a broad absorption band and large-spaced wavelengths has unique features. On the one hand, in this case, unlike the narrow absorption band, there are no special requirements for spectral characteristics of laser radiation since within the radiation bandwidth of the $\mathrm{XeCl}$ laser $(\Delta \lambda<1 \mathrm{~nm})$ [Unchino et al., 1979] the absorption band spectrum remains practically constant. On the other hand, due to significant spectral separation of radiation wavelengths there is a noticeable difference in aerosol scattering.

The expression for determining ozone concentration $n_{3}$ in this case has a more complicated form than (4) [Zuev et al., 1997] 


$$
\begin{aligned}
& n_{3}(H)=\frac{1}{\left[\sigma\left(\lambda_{1}, H\right)-\sigma\left(\lambda_{2}, H\right)\right]} \frac{d}{d H} \ln \frac{N\left(\lambda_{2}, H\right)}{N\left(\lambda_{1}, H\right)}- \\
& -\frac{1}{2\left[\sigma\left(\lambda_{1}, H\right)-\sigma\left(\lambda_{2}, H\right)\right]} \times \\
& \times \frac{d}{d H} \ln \left\{\frac{\beta\left(\lambda_{2}, H\right)}{\beta\left(\lambda_{1}, H\right)} \exp \left[\tau\left(\lambda_{1}, H\right)-\tau\left(\lambda_{2}, H\right)\right]\right\},
\end{aligned}
$$

where $\tau$ is the optical depth:

$$
\tau(\lambda, H)=\int_{0}^{H} \alpha(\lambda, h) d h .
$$

As can be seen, in this implementation of the differential absorption method it is necessary to take into account the contribution of the aerosol component. Furthermore, it is necessary to consider the temperature dependence of ozone absorption cross-sections [Zuev et al., 1997].

\section{Studying the spatiotemporal aerosol distribution at 12-100 $\mathrm{km}$ altitudes}

The main theoretical and experimental groundwork for this sensing method is presented in [Marichev, Samokhvalov, 2011; Marichev, 2012; Cheremisin et al., 2013].

The initial lidar equation in the approximation of single elastic scattering when using a monostatic sensing scheme is described by Formula (1).

The scattering ratio $R$, which is a ratio of the total backscatter coefficient to the molecular backscattering, is often considered as a parameter, from which the profile of aerosol stratification is monitored, reconstructed from echo signals:

$$
R(H)=\frac{\beta(H)}{\beta_{\mathrm{m}}(H)}=\frac{\beta_{\mathrm{a}}(H)+\beta_{\mathrm{m}}(H)}{\beta_{\mathrm{m}}(H)} .
$$
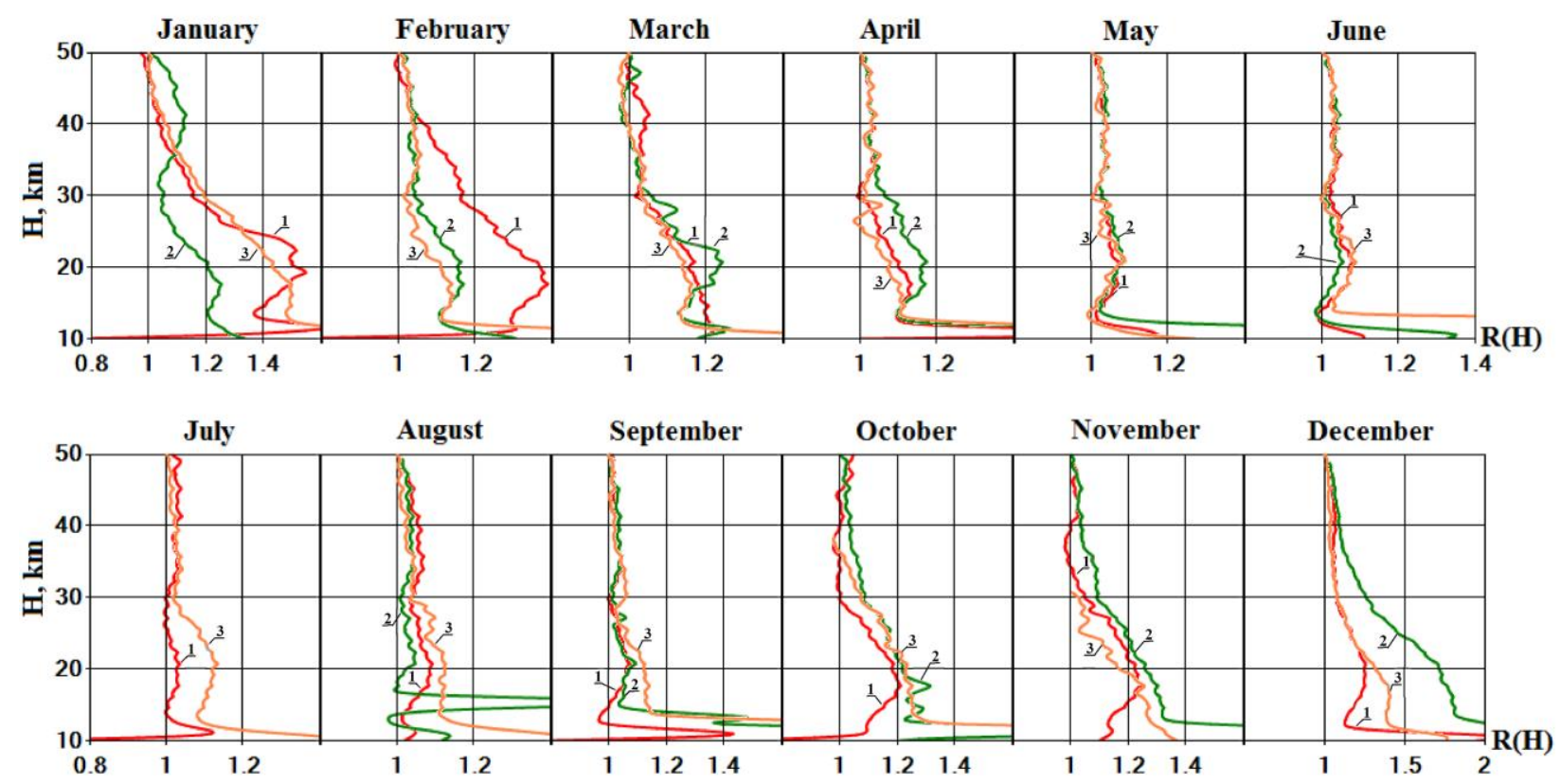

Figure 6. Monthly average profiles of vertical aerosol stratification for 2016-2018, shown by the parameter of aerosol scattering ratio $R(H): 1-2016 ; 2-2017 ; 3-2018$
In the presence of aerosol at a certain altitude $R(H)>1$; in the absence of it, $R(H) \approx 1$ within the measurement error. From (1) the scattering ratio is determined as

$$
R(H)=\frac{\left[N(H)-N_{\mathrm{TM}}\right] H^{2}}{C T^{2}(H) \beta_{\mathrm{m}}(H)} .
$$

In Expression (5), echo signals $N(H)$ and noise $N_{\mathrm{tm}}$ are taken from lidar measurements, $T(N)$ is determined from model data, which can be adjusted directly by lidar data, $\beta_{\mathrm{m}}(H)$ is found from atmospheric models or from addimental constant $C$ generally remains unknown. It is determined using a procedure for normalizing $R(H)$, which involves finding the minimum of $R(H)$ in the altitude range, where $N(H), T^{2}(H)$, and $\beta_{\mathrm{m}}(H)$ can be fairly welldetermined. For $H_{k}$, where $R(H)$ assumes a minimum value of $R_{\mathrm{m}}$, a backscatter signal is believed to be generated mainly due to the molecular scattering and $R_{\mathrm{m}}$ is close to unity. Given the above normalization, the expression for $R(H)$ takes the form

$$
R(H)=\frac{\left[N(H)-N_{\mathrm{TM}}\right] H^{2} \beta_{\mathrm{m}}\left(H_{k}\right)}{\left[N\left(H_{k}\right)-N_{\mathrm{TM}}\right] H_{k}^{2} \beta_{\mathrm{m}} T^{2}\left(H \div H_{k}\right)} R_{k} .
$$

Figure 6 shows scattering ratio profiles obtained by the IAO SB RAS lidar with the $1 \mathrm{~m}$ receiving mirror.

\section{CONCLUSION}

The analysis of technologies offered for the MS lidar included into the Heliogeophysical Complex of RAS and designed for the round-the-clock monitoring of thermodynamic parameters and aerosol-gas composition tional measurements, e.g. radiosonde ones. The instru- 
of the mesosphere, shows that they can be realized in practice, thus providing information about the state of the atmosphere in the $10-100 \mathrm{~km}$ altitude range. The presented version of the MS lidar uses different laser sources in the 350-1100 $\mathrm{nm}$ range and corresponding narrowband high-sensitivity detectors of lidar signals. Such a wide spectral range is necessary for implementing various laser sensing methods when receiving information about remote atmospheric layers. The problem of combining various measurement methods (techniques) for one receiving antenna will be solved by, firstly, spectral selection, and, secondly, using the multilobe antenna pattern.

Technical configuration of the MS lidar will enable us to upgrade and modify measurement procedures, using more advanced technical facilities. To automate the operation of the MS lidar it is reasonable to integrate it with a ceilometer, all-sky camera, and meteorological visibility range detector. The inclusion of an all-roundlooking aerosol lidar in the MS lidar will also provide information about the troposphere.

The work was carried out under the state task of IAO SB RAS (Project No.1310145-6 AAAA-A17-11702). Studies with the lidar with a $1 \mathrm{~m}$ mirror, performed by Marichev V.N., were supported by RFBR grant No. 1945-700008.

\section{REFERENCES}

Bondarenko S.L., Burlakov V.D., Grishaev M.V., Zuev V.V., Marichev V.N., Pravdin V.L. Laser sensing of the mesosphere at the Siberian lidar station. Optika atmosfery i okeana [Atmospheric and Oceanic Optics]. 1994, vol. 7, no. 11-12, pp. 1652-1655. (In Russian).

Browell E.V., Wilkerson T.D., Mcilrath T.J. Water vapor differential absorption lidar development and evolution. Applied Optics. 1979, vol. 18, no. 20, pp. 3474-3483. DOI: 10.1364/ AO.18.003474.

Burlakov V.D., Elnikov A.V., Zuev V.V., Marichev V.N., Pravdin V.L., Smirnov S.V., Stolyarova N.A. Lidar observations of the stratospheric ozone and aerosol in Tomsk $\left(56^{\circ} \mathrm{N}\right.$, $85^{\circ} \mathrm{E}$ ) following the eruption of the Pinatubo volcano. Optika atmosfery i okeana [Atmospheric and Oceanic Optics]. 1993 vol. 6, no. 10, pp. 1224-1233. (In Russian).

Czin Czyao, Gotao Yan, Czihun Van, Syueu Chen, Facyun Li. Sporadic potassium layers and their relationship with sporadic E-layers in the mesopause region above Beijing (China). Solnechno-zemnaya fizika [Solar-Terr. Phys]. 2017, vol. 3, no. 2, pp. 64-69. DOI: 10.12737/22597.

Cheremisin A.A., Marichev V.N., Novikov P.V. Polar stratospheric cloud transfer from Arctic regions to Tomsk in January, 2010. Optika atmosfery i okeana [Atmospheric and Oceanic Optics]. 2013, vol. 26, no. 2, pp. 93-99. (In Russian).

Elnikov A.V., Zuev V.V., Marichev V.N., Tsaregorodtsev S.I. First results of lidar observations of stratospheric ozone above western Siberia. Optika atmosfery $i$ okeana [Atmospheric and Oceanic Optics]. 1989, vol. 2, no. 9, pp. 995-996. (In Russian).

Elnikov A.V., Zuev V.V., Kataev M.Yu., Marichev V.N., Micel A.A. Sensing of stratospheric ozone with an UV bifrequency DIAL: methods for solving the inverse problem and results of the field experiment. Optika atmosfery $i$ okeana [Atmospheric and Oceanic Optics]. 1992, vol. 5, no. 6, pp. 576-587. (In Russian).
Kaul B.V. Mnogovolnovoi lidar dlya zondirovaniya atmosfery [Multi-wave lidar for sensing the atmosphere]. Auth. Certificate no. 1345861, 1987. (In Russian).

Kawahara T.D., Kitahara T., Kobayashi F., Saito Y., Nomura A. Sodium temperature lidar based on injection seeded Nd:YAG pulse lasers using a sum-frequency generation technique. Opt. Express. 2011, vol. 19, pp. 3553-3561.

Marichev V.N. Lidar investigations of stratospheric warming events above Tomsk in 2008-2010. Optika atmosfery $i$ okeana [Atmospheric and Oceanic Optics]. 2011a, vol. 24, no. 5, pp. 386-391. (In Russian).

Marichev V.N. Investigation into features of manifestation of winter stratospheric warming events over Tomsk from the data of lidar temperature measurements in 2010-2011. Optika atmosfery i okeana [Atmospheric and Oceanic Optics]. 2011b, vol. 24, no. 12, pp. 1041-1046. (In Russian).

Marichev V.N. Investigation of variability of the background aerosol vertical structure above Tomsk based on lidar observations in 2010-2011. Optika atmosfery i okeana [Atmospheric and Oceanic Optics]. 2012, vol. 25, no. 11, pp. 976-984. (In Russian).

Marichev V.N. The analysis of the air density and temperature behaviour in the stratosphere above Tomsk in periods of perturbed and quiet states performed according to the results of lidar measurements. Optika atmosfery $i$ okeana [Atmospheric and Oceanic Optics]. 2013, vol. 26, no. 9, pp. 783-792. (In Russian).

Marichev V.N., Samokhvalov I.V. Lidar observations of aerosol volcanic layers in stratosphere of Western Siberia in 20082010. Optika atmosfery $i$ okeana [Atmospheric and Oceanic Optics]. 2011, vol. 24, no. 3, pp. 224-231. (In Russian).

Marichev V.N., Zuev V.V., Grishaev M.V., Smirnov S.V. Lidar and spectrophotometric measurements of vertical distribution of ozone, nitrogen dioxide, and temperature in the stratosphere over Tomsk (Western Siberia). Optika atmosfery $i$ okeana [Atmospheric and Oceanic Optics]. 1996, vol. 9, no. 12, pp. 1604-1608. (In Russian).

Matvienko G.G., Bobrovnikov S.M., Kaul B.V. Application of lidars to study the middle and upper atmosphere. Solnechno-zemnaya fizika [Solar-Terr. Phys]. 2010, vol. 16, pp. 76-81. (In Russian).

Matvienko G.G., Kaul B.V., Marichev V.N., Burlakov V.D., Bobrovnikov S.M., Yakovlev S.V. Lidar for the heliogeophysical complex of the RAS. Technical appearance. Sbornik trudov XXIV Vserossiiskoi konferentsii "Rasprostranenie radiovoln (RRV-24)" [Proceedings of the XXIV All-Russian Conference "Radio Wave Propagation (RWP-24)"]. 2014, pp. 13-18. (In Russian).

Matvienko G.G., Balin YU.S., Bobrovnikov S.M., Romanovskii O.A., Kohanenko G.P., Samoilova S.V., Penner I.E., Gorlov E.V., Zharkov V.I., Sadovnikov S.A., Harchenko O.V., Yakovlev S.V., Bazhenov O.E., Burlakov V.D., Dolgii S.I., Makeev A.P., Nevzorov A.A., Nevzorov A.V. Sibirskaya lidarnaya stantsiya: apparatura $i$ rezul'taty [Siberian lidar station: equipment and results]. Tomsk, IOA SB RAS Publ., 2016, 440 p. (In Russian).

Polekh N.M., Chernigovskaya M.A., Yakovleva O.E. On the formation of the F1 layer during sudden stratospheric warming events. Solar-Terr. Phys. 2019, vol. 5, no. 3, pp. 119-129. DOI: 10.12737/stp-53201914.

Polyakova A.S., Chernigovskaya M.A., Perevalova N.P. Study of the response of the ionosphere to sudden stratospheric warming in the Asian region of Russia. Solnechno-zemnaya fizika [Solar-Terr. Phys]. 2015, vol. 1, no. 4, pp. 47-57. DOI: 10.12737/13527. (In Russian).

Rees D., Barnett J.J., Labitzke K. COSPAR International Reference Atmosphere, 1986: Part 2: Middle Atmosphere Models. Adv. Space Res. 1990, vol. 10, no. 12, p. 525. 
Schoch A., Baumgarten G., Fiedler J. Polar middle atmosphere temperature climatology from Rayleigh lidar measurements at ALOMAR $\left(69^{\circ} \mathrm{N}\right)$. Ann. Geophys. 2008, vol. 26, no. 7, pp. 1681-1698. DOI: 10.5194/angeo-26-1681-2008.

Spelsberg D., Meyer W. Dynamic multipole polarizabilities, reduced spectra, and interaction coefficients for $\mathrm{N}_{2}$ and CO. Chem. Phys. 1999, vol. 111, no. 21, pp. 9618-9624. DOI: 10.1 63/1.480336.

Unchino O., Maeda M., Hirono M. Applications of excimer lasers to laser-radar observations of the upper atmosphere. JEEE J. Quant. Electr. 1979, vol. QE-15, no. 10, pp. 1094 1107. DOI: 10.1109/JQE.1979.1069905.

von Zahn U., von Cossart G., Fiedler J., Fricke K.H., Nelke G., Baumgarten G., Rees D., Hauchecorne A., Adolfsen K. The ALOMAR Rayleigh/Mie/Raman lidar: objectives, configuration, and performance. Ann. Geophys. 2000, vol. 18, pp. 815-833. DOI: 10.1007/s00585-000-0815-2.

Zuev V.V., Zuev V.E. Distancionnoe opticheskoe zondirovanie atmosfery [Remote optical sensing of the atmosphere]. St Petersburg, Hydrometeoizdat Publ., 1992. 232 p. (In Russian).

Zuev V.E., Makushkin Yu.S., Marichev V.N., Mitsel A.A., Samokhvalov I.V., Sosnin A.V. Laser sensing of atmospheric humidity profile. DAN [Reports of the Academy of Science]. 1981, vol. 251, no. 6, pp. 1338-1342. (In Russian).

Zuev V.V., Zuev V.E., Makushkin Yu. S., Marichev V.N., Mitsel A.A. Laser sensing of atmospheric humidity: experiment. Applied Optics. 1983, vol. 22, no. 23, pp. 3742-3746. DOI: $10.1364 / A O .22 .003742$.

Zuev V.V., Marichev V.N., Bondarenko S.L., Dolgii S.I., Sharabarin E.V. Preliminary results of tropospheric temperature sensing using a raman lidar on the first vibrationalrotational transition of nitrogen molecules. Optika atmosfery $i$ okeana [Atmospheric and Oceanic Optics]. 1996a, vol. 9, no. 12, pp. 1609-1611. (In Russian).
Zuev V.V., Marichev V.N., Dolgii S.I., Sharabarin E.V. Some experimental results of lidar sensing of the ozone and temperature in the troposphere and stratosphere. Optika atmosfery i okeana [Atmospheric and Oceanic Optics]. 1996b, vol. 9, no. 8, pp. 1123-1125. (In Russian).

Zuev V.V., Kataev M.Yu., Marichev V.N. Technique for sconstructing the ozone profiles from UV lidar data: correction for aerosol and temperature stratification. Optika atmosfery i okeana [Atmospheric and Oceanic Optics]. 1997, vol. 10, no. 9, pp. 1103-1111. (In Russian).

Yasyukevich A.S., Klimenko M.V., Kulikov Yu.Yu., Klimenko V.V., Bessarab F.S., Koren'kov Yu.N., Marichev V.N., Ratovsky K.G., Kolesnik S.A. Changes in the middle and upper atmosphere parameters during the January 2013 sudden stratospheric warming. Solar-Terr. Phys. 2018, vol. 4, no. 4, pp. 62-75. DOI: $10.12737 /$ stp-44201807.

How to cite this article

Matvienko G.G., Marichev V.N., Bobrovnikov S.M., Yakovlev S.V., Chistilin A.Yu., Sautkin V.A. Mesostratospheric Lidar for the Heliogeophysical Complex. Solar-Terrestrial Physics. 2020. Vol. 6. Iss. 2. P. 74-83. DOI: 10.12737/stp-62202007. 